\title{
An interactive virtual reality physics instructional environment based on Vygotskian Educational Theory
}

\author{
Michael Cowling, Robert Vanderburg \\ Central Queensland University
}

Physics Education is a popular application for Virtual Reality (VR), with many simulations being available for students to manipulate objects in virtual space. However, most of these applications take a Piagetian approach to learning, instructing first in a traditional way and then exposing students to VR in a sandbox environment without the instructor present. This paper proposes a design for a VR physics simulation that takes a Vygotskian approach using Zone of Proximal Development (ZPD) and scaffolding to teaching physics, allowing the students and instructor to collaborate in virtual space. Using gravity and circular motion as a case study, this paper discusses a design to facilitate this learning comprising a virtual universe with control of planet placement and size, external satellite placement and size, as well as gravitational forces acting on these objects, along with a design-based research (DBR) research design to evaluate both usability and learning for the intervention.

Keywords: Virtual Reality, Physics Education, Zone of Proximal Development, Vygotsky

\section{Introduction}

Virtual Reality as a field has been studied for many years, and many studies have been conducted on the applications and effectiveness of VR in education and training since the 1980s (McLellan, 1996, 2003). For example, Hu-Au and Lee (2007) showed that virtual reality can play a unique role in addressing complexity in education as a hands-on tool for learning, and Norriafshar et. al., (2014), have shown the use of virtual reality in education in nursing and business. But it's only recently that evidence has been shown that virtual reality can have a positive effect on engagement, with Parong \& Mayer (2018) identifying that virtual reality can be more effective than traditional teaching in satisfying student motivation and engagement.

This situation provides an opportunity to explore VR education in a new way. Given the findings that motivation and engagement is higher using VR, can an application of educational theories mixed with VR be used increase in engagement and increase learning outcomes for students? Traditionally VR has been used in a sandbox component. We are looking to generate a VR environment where a teacher can interact and manipulate the physical constructs taught in Physics while providing Vygotskian teaching theories. In this paper, we are proposing that VR visualization can assist the learner in understanding concepts related to physics education, in particular as relates to senior high school students and first year undergraduate students learning orbital motion and other force related concepts key to disciplines such as engineering. The research question driving this project is "How well does a VR environment for physics education utilising Vygotskian concepts be used to enhance students' learning?".

\section{Related Work}

Learning and teaching are undergoing drastic changes due to technological advances in the education field (Bereiter and Scardamalia, 2014). Disengagement is considered to be a key factor influencing student dropout rates (Appleton et al., 2006). But there is growing interest in 3D immersion and VR applications, especially 360 VR videos where students can dive themselves into an immersive playback experience (Hosseini \& Swaminathan, 2016). Innovative new technologies such as virtual reality (VR) are not just altering the field of education for students, they are shaking up the role of educators and creating philosophical shifts in approaches to teaching and learning (Markowitz et. al., 2018). VR technology has become a powerful tool with the capability to create highly interactive 3D space environment providing users with an immersive experience eliminating the physical world by natural manipulations in real-time through multisensory channels (Mikropoulos \& Natsis, 2011).

Looking specifically at interventions in the field of Physics Education, $\mathrm{PhET}$ is a popular physics simulation software developed by Perkins et al. (2006) that uses simple $2 \mathrm{~d}$ animations to present physics concepts. 
Currently PhET contains over 50 simulations of physics concepts focused on high school and introductory college physics. However, the simulations themselves are not in a virtual environment, but rather in a simpler $2 \mathrm{~d}$ world constructed for each simulation with no indication if these simulations produced improved learning outcomes for students. In contrast, Kim, Park, Lee, Yuk \& Lee (2001) propose a solution for using VR for physics that involves a 2-dimensional web view. Simulations of wave forms, actions and reactions, harmonics and electric currents are presented, with parameters that can be manipulated. Wu, Chan, Jong \& Lin (2003) present a similar intervention.

Looking at immersive solutions, Loftin, Engleberg \& Benedetti (1993) present an immersive simulator constructed using custom graphics hardware that is tethered within a computer lab. It contained implementations for switches, sliders and control of gravity, as well as the manipulation of time as a variable. More recently, Pirker, Holly, Lesjak, Kopf \& Gutl (2019) describe a system, MaroonVR, designed to provide an immersive virtual reality physics laboratory. MaroonVR is available in both seated and room scale versions and uses VR to simulate laboratory equipment. A basic multi-user version of MaroonVR is also available.

Savage, McGrath, McIntyre, Wegener \& Williamson (2010) describe a system called Real Time Relativity that uses virtual reality to explain physics movement concepts. However, the system used (immersive or not) is unclear, and the link to the website does not work, suggesting that the tool is no longer available. Kaufmann \& Meyer (2009) describe a similar simulation that uses a custom immersive headset and an air pen to provide a sandbox environment where students can manipulate forces on objects in virtual reality. Bogusevschi, Muntean \& Muntean (2020) present results from testing a specific virtual reality simulation of the water cycle with secondary school students. The learner can be placed in either a realistic virtual world (the nature VR environment) or in an experimental VR environment to conduct an experiment.

\section{Educational Theory}

Based on our literature review, it's clear that the current research addressing VR integration to physics instruction uses a very Piagetian Approach to learning (Dinham, 2017m; Piaget, 1970; Piaget, 1950). Piagetian theory (1970, 1950) predominantly believes that students need to interact with physical properties in a self- directed environment so they can experience the struggle of new information at their own pace. It also enforces students developing their own procedures for understanding the new material. This is a powerful form of learning because the student has agency and is able to interact with the concepts at their own pace.

Piagetian theory is most aptly embraced when utilize the VR in a sandbox format.

In a sandbox format, students are instructed on the physics concepts in a traditional lecture format lacking the VR technology and are later, post-instruction, allowed to interact with predesigned VR sandbox representations of the concepts. This instructional pedagogy is Piagetian because the students are left alone to use the physics theories, without mathematical calculations, in a VR environment so they can struggle through the disequilibrium component of the concepts to derive at their own understanding of the physics curriculum.

We feel that the sandbox approach to teaching physics using VR could be enhanced by incorporating a Vygotskian component to the instructional process (Vanderburg, 2006; Vygotsky, 1989, 1986). Vygotskian theories argue instruction is conducted when a more experienced learner or instructor guides students with scaffolding through their Zone pf Proximal Development (ZPD). The Zone of Proximal Development is a zone in which a student is unable to learn the material without some form of guidance (i.e., scaffolding). A Vygotskian approach of using VR technology during the instructional component of the lesson in conjunction with the sandbox component of the lesson would improve the students learning experience while integrating VR throughout the entire instructional process. The entire lesson would be conducted in a VR simulated environment. The instruction process would happen in a VR environment in which the teacher can interact with the students guiding them through the virtual representations of the physics curriculum. This would enable the student to learn the concepts in a virtual world while receiving scaffolded virtual instruction from the teacher. Once the VR instructional process is over the, students would then be directed to sandboxes to experience the Piagetian instructional experiences (Piaget, 1970, 1950).

Adding the Vygotskian (Vanderburg, 2006; Vygotsky, 1989, 1986) instruction component to VR guided physics instruction would also improve the instructional process, because the teacher is now able to teach the mathematical calculations for the physics curriculum in the virtual environment. Using the virtual environment to teach the mathematics behind the physics principles would improve traditional instruction because the teacher can alter the sizes, distance, velocities, and forces in a visual representation to enable students to have a better grasp of how the math relates to the physics principals. The students would be able to see, in a virtual environment, the math calculations which support the physics principles taught. Adding the math calculation to the Vygotskian instructional component would allow the sandbox component of the instructional process to further be improved, 
because the sandbox activities can now have mathematical values incorporated in the previously theoretical component. Previously, the sandbox VR design could not provide mathematical explanations for the theoretical theories because that part needs to be instructed in a Vygotskian paradigm. Because the math instruction is now added to the Vygotskian interactive VR instruction, math can be added to the sandbox component of the VR instruction. Mixing these two pedagogies with VR will enable students to better understand physics curriculum while improving their mathematical understanding of physics.

Curriculum Design

The physics curriculum we will be focusing on for this VR experiment will be the Circular Motion and Gravity chapter of CK_12 Interactive Physics for High School. Specifically, we will be teaching the Circular Motion, Centripetal Force, Newtons' Universal Law of Gravity and Orbital Motion sections of the chapter.

The Circular Motion section will teach centripetal acceleration and circular motion along with the mathematical formulas and calculations for these principals, $a_{\mathrm{c}}=v_{2}, r$. In this section we will create virtual images of centripetal acceleration and circular motion with numbers representing the acceleration, velocity and radius.

The Centripetal Force section will integrate the principles from the Circular Motion section with the principles of force. So, we will incorporate the $F=m a$ formula with the $a_{c}=v_{2} / r_{\text {formula to create }} F c=m v_{2} / r$. We will then instruct the formula $\left.F C=4 \pi_{2} r m / T\right]_{2}$. The VR representation for this section will entail orbiting structures around planets in which will have the numeric values of the centripetal force, revolutions, mass and orbital period.

The section on Newton's Universal Law of Gravity will teach the concept of a gravitational constant, $G$, and the force of gravity including the formula. These concepts will be instructed using a VR representation for multiple planets in a galaxy with mathematical values for force, masses, and distance between the centres of the masses.

Finally, the Orbital Motion section will integrate the circular motion, centripetal force concepts, and the Newtons's universal law of gravity concepts to demonstrate how objects orbit a planet. The formula of gravity, $F=G \frac{m_{1} m_{2}}{r^{2}}, G=6.67 \times 10^{-11}$, will be mixed with centripetal force formula, $F C=4 \pi 2 r m / T_{2}$, to help student calculate the velocity of the orbital and the time it takes an orbital to circle a planet. The VR representation for this section will entail different planets and orbitals with numeric values centripetal force, revolutions, the masses, the distance between the centres of the masses, and orbital period.

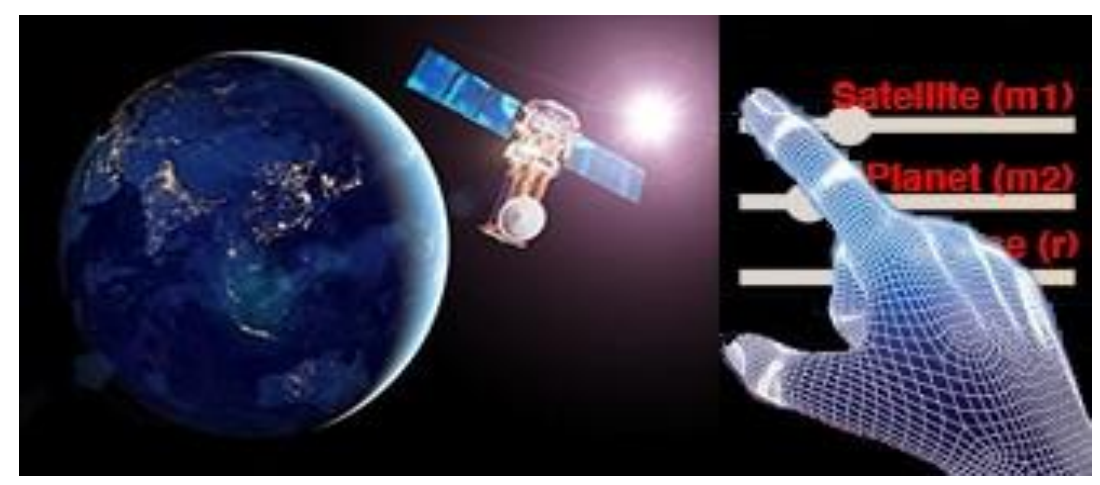

Figure 1. Gravitational Forces VR Environment

As detailed above, the intervention design will use a customised virtual reality intervention to teach circular motion, building on the work of Cowling \& Birt (2018). Specifically, the intervention will place students in a virtual universe with control of planet placement and size, external satellite placement and size, as well as gravitational forces acting on these objects. Sliders and other components will be used to allow students to dynamically change their environment. Importantly for the implementation of the Vygotskian framework, students will be able to interact with other students and the instructor in the virtual environment (via each participant wearing their own headset), allowing for instruction to occur within the environment. Students will also be given a notebook in the environment, and as part of instruction will be able to copy numerical values from the simulation 
into their note book to allow them to complete mathematical calculations using the formulas outlined above. An example of the environment is given in Figure 1.

\section{Research Design}

This research will use design-based research (DBR) methodology. This methodology supports exploration and adaptation through multiple cycles of data collection and refinement of the intervention. For instance, lessons learned over multiple terms from participant feedback and investigator analysis, repeatedly inform ongoing improvement of the intervention. Parker (2011) has demonstrated the effectiveness of DBR approaches to design and develop authentic e-learning within the higher education sector.

Within this model, we will take a Pedagogy Before Technology (PBT) approach to the development of the intervention (Cowling \& Birt, 2018). Specifically, the pedagogy of how physics concepts are taught will be engaged with in the initial stages to ensure VR is an appropriate intervention. The technology will then be implemented and PBT techniques applied to iterate on design by engaging with the problem and solution.

Within the overarching DBR methodology, this project will use a combination of qualitative and quantitative methodologies to answer our research questions. Usability testing will be conducted in-line with Birt \& Cowling (2019), whilst a pre and post testing crossover design will be used to test learning outcomes. This approach aligns with the data sources available and is well suited as it will allow identification of both the strengths and weaknesses of the VR Learning Model for Physics Education in order to improve physics teaching techniques while addressing our research questions. Finally, this study will be iterative in its methodology using DBR process which Reeves (2006) as shown in Figure 2 (adapted from Munoz, Cowling \& Birt, 2018).

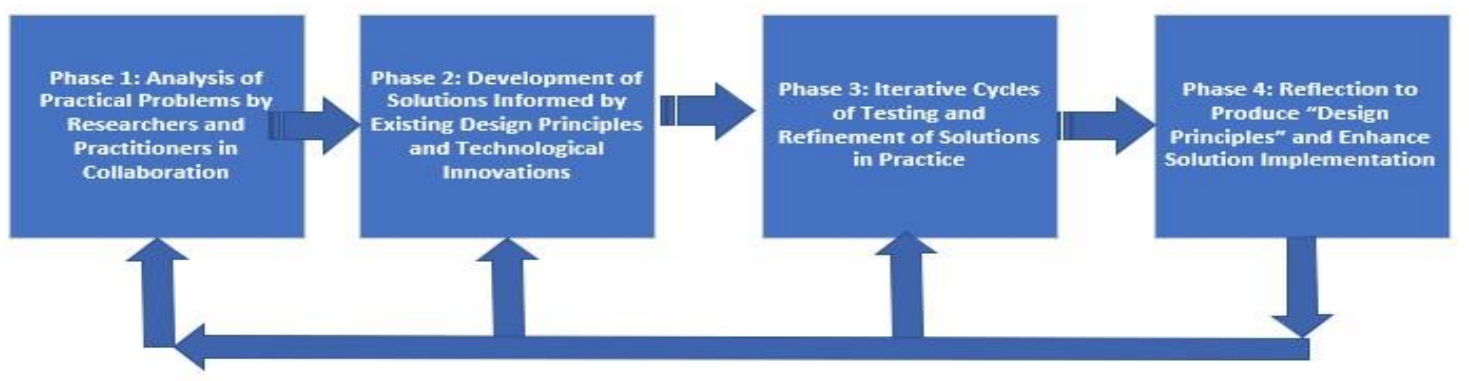

Refinement of Problems, Solutions, Methods, and Design Principles

Figure 2. Four Phases of Design Based Research (Reeves, 2006)

This research approach is being used in education to investigate innovation using technology-based initiatives, because it "embraces the complexity of learning and teaching and adopts interventionist and iterative posture towards it" (Kelly, 2004, p. 105). The research will be conducted in two loops. The 1st loop will focus on talking to teachers of the unit, designing a solution, then testing it with the experts to make sure it's suitable. The 2 nd loop will then refine the analysis and design based on the pilot with the experts, and then testing with students. Conclusion

Virtual reality is often proposed as a solution for physics related education, but often presented in a sandbox style that echoes the work of Piaget in providing an isolated environment where students construct their own learning. This paper proposes that a more effective VR environment would use the Vygotskyian ideals of socialization and constructivism to encourage interaction between students during the scaffolded instruction period. Using physics education as a case study, this paper proposes a design for a VR environment that teaches concepts of gravitational force and circular motion. Students would be able to use this VR intervention to manipulate physical objects, adjust gravitational forces, and importantly complete mathematical calculation using the resultant numerals. A DBR methodology is then proposed to evaluate effectiveness of the intervention.

\section{References}

Appleton J.J., Christenson S.L., Kim D., and Reschly, A.L. (2006). Measuring cognitive and psychological engagement: Validation of the Student Engagement Instrument. Journal of School Psychology, 44(5), 427445.

Bereiter C., and Scardamalia M. (2014). Knowledge building and knowledge creation: One concept, two hills to climb. In S. C. Tan, H. J. So, J. Yeo (Eds.), Knowledge creation in education. Information, 9, 35-52. 
Birt, J., \& Cowling, M. (2018). Assessing mobile mixed reality affordances as a comparative visualization pedagogy for design communication. Research in Learning Technology, 26, 1-25.

Bogusevschi, D., Muntean, C., \& Muntean, G. M. (2020). Teaching and Learning Physics using 3D Virtual Learning Environment: A Case Study of Combined Virtual Reality and Virtual Laboratory in Secondary School. Journal of Computers in Mathematics and Science Teaching, 39(1), 5-18.

Cowling, M., \& Birt, J. (2018). Pedagogy before technology: A design-based research approach to enhancing skills development in paramedic science using mixed reality. Information, 9(2), 29.

Dinham, S. (2017). The Lack of an Evidence Base for Teaching and Learning: Fads, myths, legends, ideology and wishful thinking. Professional Voice, 11(3), 17-25.

Haryadi, R., \& Pujiastuti, H. (2020). PhET simulation software-based learning to improve science process skills. In Journal of Physics: Conference Series, 1521, 022017.

Hosseini, M., \& Swaminathan, V. (2016, December). Adaptive 360 VR video streaming: Divide and conquer. In 2016 IEEE International Symposium on Multimedia (ISM), 107-110.

$\mathrm{Hu}-\mathrm{Au}$ E., and Lee J.J. (2017). Virtual reality in education: a tool for learning in the experience age. International Journal on Innovation in Education, 4(4), 215-226.

Kaufmann, H., \& Meyer, B. (2009). Physics Education in Virtual Reality: An Example. Themes in Science and Technology Education, 2, 117-130.

Kelly A.E. (2004). Design research in education: Yes, but is it methodological? Journal of the Learning Sciences, 13(1), 115-128.

Kim, J. H., Park, S. T., Lee, H., Yuk, K. C., \& Lee, H. (2001). Virtual reality simulations in physics education. Interactive Multimedia Electronic Journal of Computer-Enhanced Learning, 3(2), 1-7.

Loftin, R. B., Engleberg, M., \& Benedetti, R. (1993, October). Applying virtual reality in education: A prototypical virtual physics laboratory. In Proceedings of 1993 IEEE Research Properties in Virtual Reality Symposium, 67-74.

Markowitz D.M., Laha R., Perone B.P., Pea R.D., and Bailenson J.N. (2018). Immersive virtual reality field trips facilitate learning about climate change. Journal of Frontiers in Psychology. 9, 2364.

McLellan H. (1996). Virtual realities. In D.H. Jonassen (Ed.), Handbook of research for educational communications and technology. 457-487. New York: Macmillan Library Reference, USA.

McLellan H. (2003). Virtual realities. In D. H. Jonassen \& P. Harris (Eds.), Handbook of research for educational communications and technology (2nd ed.), 461-498. Mahwah, NJ: Lawrence Erlbaum.

Mikropoulos T.A., and Natsis A. (2011). Educational virtual environments: A ten-year review of empirical research (1999-2009). Computers \& Education, 56(3), 769-780.

Nooriafshar, M., Williams, R., \& Maraseni, T. N. (2004, August). The use of virtual reality in education. In Proceedings of the 7th American Society of Business and Behavioral Sciences International Conference (ASBBS 2004). American Society of Business and Behavioral Sciences (ASBBS).

Parong, J., \& Mayer, R. E. (2018). Learning science in immersive virtual reality. Journal of Educational Psychology, 110(6), 785.

Perkins, K., Adams, W., Dubson, M., Finkelstein, N., Reid, S., Wieman, C., \& LeMaster, R. (2006). PhET: Interactive simulations for teaching and learning physics. The Physics Teacher, 44(1), 18-23.

Piaget, J. (1950). The psychology of intelligence. Routledge.

Piaget, J. (1970). Genetic epistemology. The Norton Library.

Pirker, J., Holly, M., Lesjak, I., Kopf, J., \& Gütl, C. (2019). MaroonVR-An Interactive and Immersive Virtual Reality Physics. In Learning in a digital world: Perspective on interactive technologies for formal and informal education (p. 213). Springer.

Reeves, T. C. (2006). Design research from the technology perspective. JV Akker, K. Gravemeijer, S. McKenney ve N. Nieveen (Eds.), Educational design research içinde, 86-109. Routledge.

Savage, C., McGrath, D., McIntyre, T., Wegener, M., \& Williamson, M. (2010, July). Teaching physics using virtual reality. In AIP Conference Proceedings 1263 (1), pp. 126-29). American Institute of Physics.

Vanderburg, R. M. (2006). Reviewing research on teaching writing based on Vygotsky's theories: What we can learn. Reading and Writing Quarterly, 22(4), 375-393. https://doi.org/10.1080/10573560500455778

Vygotsky, L. S. (1986). Thought and language. MIT Press.

Vygotsky, L. S. (1989). Mind in society (M. Cole, V. John-Steiner, S. Scribner, \& E. Souberman (eds.)). Harvard university press. https://doi.org/10.4244/EIJY14M06_06

Wu, Y., Chan, T., Jong, B., \& Lin, T. (2003, July). A web-based virtual reality physics laboratory. In Proceedings 3rd IEEE International Conference on Advanced Technologies, 455. IEEE.

Cowling, M. \& Vanderburg, R. (2020). An interactive virtual reality physics instructional environment based on Vygotskian Educational Theory. In S. Gregory, S. Warburton, \& M. Parkes (Eds.), ASCILITE's First Virtual Conference. Proceedings ASCILITE 2020 in Armidale (pp. 168-173). https://doi.org/10.14742/ascilite2020.0116 
Note: All published papers are refereed, having undergone a double-blind peer-review process.

The author(s) assign a Creative Commons by attribution licence enabling others to distribute, remix, tweak, and build upon their work, even commercially, as long as credit is given to the author(s) for the original creation.

(C) Cowling, M. \& Vanderburg, R. 2020 